\title{
A LINGUAGEM DA ADMINISTRAÇÃO PÚBLICA: UM ESTUDO SOBRE A ABORDAGEM PÓS-MODERNA
}

POSTMODERN IDEAS IN THE PUBLIC ADMINISTRATION FIELD

\section{RESUMO}

Nas últimas décadas, um número crescente de estudiosos nas diversas áreas das ciências humanas tem incorporado ideias relacionadas ao chamado pensamento pós-moderno. Na área de Administração Pública, a incursão no pensamento pós-moderno tem sido relativamente pouco explorada no plano internacional. No Brasil, são escassos os estudos que relacionam a abordagem pós-moderna à investigação em administração pública. O presente estudo procura apresentar e discutir análises teóricas que incorporaram as ideias da pós-modernidade no campo da Administração Pública, concluindo que, embora a apropriação dessas ideias não seja tarefa fácil, há de se considerar as possíveis contribuições principalmente com relação a aspectos metodológicos e analíticos que possam fortalecer a pesquisa em administração pública.

PALAVRAS-CHAVE Teoria da administração pública, administração pública pós-moderna, pós-positivismo, linguagem, construtivismo.

\author{
Ana Cláudia Niedhardt Capella acapella@terra.com.br \\ Doutora em Ciências Sociais, professora do Departamento de Administração Pública da Unesp, campus de Araraquara
}

Artigo submetido no dia 06.10.2011 e aprovado em 16.12.2011.

ABSTRACT Over the last decades, a growing number of scholars from humanities have explored ideas from the postmodern perspective. At the international level, few studies have been undertaken in the public administration field. In Brazil, few articles have been influenced by postmodern ideas. This article presents and discusses theoretical analysis influenced by postmodern ideas in the public administration field, concluding that this appropriation is difficult but worthwhile, especially regarding methodological and analytical issues which may strengthen public administration research.

KEYWORDS Public administration theory, postmodern public administration, postpositivism, language, social constructivism. 


\section{ANA CLÁUDIA NIEDHARDT CAPELLA}

\section{INTRODUÇÃo}

Nas últimas décadas, um número crescente de estudiosos nas diversas áreas das Ciências Humanas tem incorporado ideias relacionadas ao chamado pensamento pós-moderno nos campos da Economia, Estudos Organizacionais, Administração, Sociologia, Relações Internacionais, Políticas Públicas, entre outros. O termo pós-moderno é ambíguo e controverso, assume distintos significados e envolve um conjunto amplo de ideias. Por vezes identificado com perspectivas "pós-positivistas", "pós-empiricistas", "pós-estruturalistas", entre outras denominações, o pós-modernismo, neste trabalho, relaciona-se a uma forma de pensar que destaca a importância da linguagem, o contexto das interações humanas, a construção social da realidade e a impossibilidade de manutenção de verdades universais sobre qualquer fenômeno sociall $^{1}$. Não se trata de uma "escola de pensamento" estruturada, nem de uma explicação alternativa à perspectiva moderna, mas de um estilo de pensamento marcado por algumas características, como veremos adiante. Na administração pública, a ideia de pós-modernidade está relacionada à negação do positivismo ainda predominante nas teorias da área. "Postmodern public administration theory can be most easily understood as the antithesis of positivism and the logic of objective social science", afirmam Frederickson e Smith (2003, p. 127) após analisarem as principais abordagens teóricas empregadas no campo da Administração Pública.

$\mathrm{Na}$ área de Administração Pública, a incursão no pensamento pós-moderno tem sido relativamente pouco explorada no plano internacional, reunindo um grupo pequeno de teóricos e publicações especializadas principalmente nos Estados Unidos (BOGASON, 2001; 2007). No Brasil são escassos os estudos que relacionam a abordagem pós-moderna à investigação na área. Uma das razões para a limitada incorporação das ideias pós-modernas reside nas dificuldades da pesquisa e da teorização em administração pública. A área é confrontada, historicamente, com as dificuldades de acumulação e sistematização do conhecimento, com as limitações provocadas pelo viés normativo predominante nas investigações, elementos que refletem a própria dificuldade da área em afirmar-se como uma disciplina (SOUZA, 1998). Assim, diferentemente de outras áreas das Ciências Humanas nas quais as ideias pós-modernas se desenvolveram de forma mais intensa nos últimas décadas, as próprias dificuldades no desenvolvimento teórico no campo da Administração Pública ajudariam a explicar a baixa aderência a esse referencial. Adicionalmente, é preciso considerar outro aspecto. O pensamento pós-moderno representa, em grande parte, uma ruptura com as ideias dominantes da área de Administração Pública, o que ajuda a explicar a dificuldade de adesão ao referencial pós-moderno. A administração pública, como "arte, ciência e profissão" - para lembrar os diferentes aspectos constitutivos descritos por Lynn (1996) - é, ela própria, um produto da modernidade e, talvez por essa razão, mais resistente à visão pós-moderna do que outras disciplinas das Ciências Humanas. É precisamente nesse aspecto que reside a maior possibilidade de contribuição do referencial pós-moderno para a área. Os autores alinhados com a perspectiva pós-moderna oferecem uma crítica substancial tanto das teorias quanto das práticas convencionais na área de Administração Pública, desenvolvendo argumentos capazes de proporcionar novos olhares sobre a área, estimulando o pensamento crítico sobre as organizações públicas.

O presente artigo tem como objetivo apresentar e discutir as contribuições do pensamento pós-moderno às abordagens tradicionais em administração pública. Trata-se de um estudo introdutório, que busca contribuir para a discussão de um tema que ainda carece de reflexão 
no país. Assim, apesar de a crítica pós-moderna ter influenciado diferentes áreas de conhecimento nas ciências Sociais, este estudo concentra-se na incorporação dessas ideias na Administração Pública, como campo de conhecimento e como disciplina acadêmica. Para tanto, analisaremos dois estudos considerados representativos no sentido do questionamento das teorias modernas de administração pública e da busca de desenvolvimento de alternativas baseadas nas categorias pós-modernas. Esses estudos foram selecionados tendo em vista o posicionamento de seus autores no campo da Administração Pública, bem como sua influência em trabalhos posteriores desenvolvidos na área sobre o tema. O estudo de Farmer (1995) destaca os limites das teorias modernas de administração pública e apresenta as principais características do pensamento pós-moderno para a área. Miller e Fox $(1995 ; 2007)$ concentram-se não apenas nas teorias, mas também nas práticas cotidianas da administração pública para confrontá-las com seus limites, lançando mão do arsenal explicativo do pensamento pós-moderno.

Os estudos aqui analisados, ainda pouco conhecidos no Brasil, não consistem em abordagens que vislumbram no pensamento pós-moderno uma oportunidade de produzir ideias baseadas em modismos, de forma inconsequente:

"These authors [FARMER: 1995 e FOX e MILLER: 1995] are not new to the field, are not the young Turk staring down the aged, but are experienced and wellpublished colleagues. This sort of experimentation with a new approach by journeymen and senior scholars does not indicate a fad" (TENNERT e WEAVER, 2000, p. 321).

Esses autores, obviamente, não estão sozinhos na reflexão crítica sobre as teorias e práticas da administração pública. Outros estudos, também desenvolvidos no campo de Administração Pública (notadamente nos Estados Unidos) abordam temas ligados ao referencial pós-moderno, porém de forma menos explícita que os dois trabalhos mencionados. Nesse sentido, podemos lembrar a pesquisa de Harmon (1981), precursor da ideia de que o desenvolvimento de um "paradigma alternativo", fundamentado no pós-positivismo e na visão de construção social da realidade para a área de Administração Pública seria essencial para o amadurecimento teórico do campo. Podemos ainda destacar a análise de White (1999), que investiga a produção do conhecimento no campo de Administração Pública, apontando os limites da tradição positivista e os benefícios de perspectivas pós-positivistas, principalmente por meio da adoção das abordagens interpretativa e crítica. De forma bastante semelhante, Jun (2006) baseia-se em conceitos da fenomenologia, hermenêutica, teoria crítica e ideias relacionadas ao pensamento pós-moderno para analisar fenômenos cada vez mais complexos, para os quais as teorias da administração pública não têm oferecido explicações adequadas quando confrontadas com situações paradoxais, consequências não intencionais e resultados contraditórios, cenário cada vez mais presente no cotidiano das organizações públicas. São ainda relevantes os estudos de McSwite (1997)² sobre a importância do "pragmatismo colaborativo", por meio do qual a participação popular poderia ser ampliada, fortalecendo a legitimidade da administração pública; a análise de Spicer (2001) que questiona a visão de Estado predominante nas teorias de administração pública no contexto da pós-modernidade; as perspectivas feministas na administração públicas desenvolvidas por Stivers (2002) e que criticam a lógica burocrática. Apesar de oferecerem críticas importantes às teorias predominantes na área de Administração Pública, essas pesquisas não estão diretamente relacionadas à incorporação do pensamento pós-moderno, como Farmer (1995) e Miller e Fox $(1995 ; 2007)$ evidenciam em suas análises. Assim, no presente trabalho, 
concentraremos nossa atenção nos estudos mais diretamente relacionados à ideia de pós-modernidade, em busca de referenciais críticos que possam contribuir para um debate sobre o campo da Administração Pública, seus limites e possibilidades na atualidade.

\section{FARMER: A CENTRALIDADE DA LINGUAGEM E AS TEORIAS DE ADMINISTRAÇÃO PÚBLICA}

Uma das influências mais marcantes do pensamento pós-moderno consiste na ênfase na linguagem e em sua importância na construção da realidade que as palavras são capazes de produzir. Para os autores pós-modernos, a forma como organizamos uma sequência de palavras em frases, parágrafos e páginas, influencia a forma como produzimos sentido sobre a realidade. Além disso, o significado não reside propriamente nas palavras, mas na relação destas com seu contexto: um termo pode adquirir um sentido num texto sobre economia e outro na administração pública. O conceito de "jogos de linguagem" designa as regras utilizadas em determinadas comunidades e que direcionam o sentido das palavras utilizadas em cada um desses contextos ${ }^{3}$.

Farmer se apropria do pensamento pós-moderno ao destacar que as teorias de administração pública são compostas, sobretudo, pela linguagem, "lente" pela qual podemos enxergar o mundo: "We are condemned to see the world through the eyeglasses of a language" (FARMER, 1995, p. 19). As teorias de administração pública são, para o autor, produtos dos "jogos de linguagem" criados, reproduzidos e compartilhados por uma comunidade de especialistas. É a linguagem que permite o estabelecimento de entendimentos compartilhados a respeito de palavras como "servidores públicos", "burocracia", "eficiência".

As teorias, explica o autor, são construídas por meio de proposições ou hipóteses originadas em observações, processo no qual o observador está sujeito à linguagem. Durante a estruturação de seus achados, novamente o observador defronta-se com a linguagem. A neutralidade científica é, para o autor, insustentável, uma vez que o observador dos fatos é, ele próprio, aquele que organiza e expressa esses fatos, por meio da linguagem. "Facts cannot speak for themselves. For one thing, facts can neither speak nor write; speaking requires a speaker, and both speaking and writing require a subject who has a language" (FARMER, 1995, p. 18). Assim como os fatos, a realidade da administração pública é entendida como sendo socialmente construída, baseada na linguagem.

As teorias da administração pública constituem, portanto, a linguagem da administração pública (FARMER, 1995, p. 1). Para analisar essa linguagem, o autor se apóia no "paradigma reflexivo", forma de pensar bastante difundida entre autores pós-modernos, segundo a qual as explicações que podemos oferecer sobre a realidade não são isentas de valor. Sendo assim, devemos explorar de que forma as realidades sociais são construídas por meio da análise das interações nas quais são produzidos os sentidos, principalmente o uso da linguagem. Para Farmer, o paradigma reflexivo possibilita a compreensão das características linguísticas empregadas no entendimento dos fenômenos da administração pública, ou seja, no processo de construção social das teorias do campo.

\footnotetext{
Reflexive interpretation is concerned with why we see (understand) what we are seeing (understanding) and with the possibilities for seeing (understanding) something different by changing the lens [...] The term lens here refers to the mass of assumptions, the underlying theoretical framework, through which we look. We cannot escape having a framework, but we need to be conscious of the way that it shapes
} 
(creates) what we see. A leading concern is why we are seeing what we are seeing and whether we could see it differently; it is reflexive interpretation (FARMER, 1995, p. 13).

O estudo das "lentes" - pressupostos socialmente construídos e expressos pela linguagem por meio das quais enxergamos os fenômenos do campo da Administração Pública envolve a hermenêutica. A hermenêutica, ou seja, a investigação da relação entre a linguagem e o conhecimento, baseia-se na interpretação de textos escritos ou não - linguagem manifesta em forma de práticas ou arranjos sociais. Para o estudo da administração pública, isso significa analisar o conjunto de teorias que orientam as ações dos burocratas - a linguagem da administração pública.

Dessa forma, baseado no método reflexivo, Farmer (1995) se concentra na análise das teorias de administração pública em dois momentos: no contexto da modernidade e da pós-modernidade. A linguagem da administração pública é um caso paradigmático de modernidade (FARMER, 1995, p. 48) marcada, sobretudo, pelo racionalismo e pelo conhecimento objetivo. Tais características, segundo o autor, limitaram o poder da teoria tanto em prover explicações quanto em contribuir para a resolução dos problemas das burocracias públicas.

Para o autor, existem cinco limites claros nas teorias modernas de administração pública. O particularismo impõe limitações à investigação na área ao fragmentar o conhecimento, como parte do processo moderno de especialização e autonomização das disciplinas. Tal fragmentação do conhecimento, segundo o autor, gera verdadeiros "pontos cegos" na agenda de pesquisa do campo, uma vez que algumas questões são sistematicamente ignoradas. Três aspectos do particularismo são apontados como especialmente limitadores para a administração pública moderna. Uma primeira versão do particularismo destacada pelo autor é o nacionalismo americano. Considerando que os estudos em administração pública no século XX consistem basicamente em um produto americano, voltado para aquela realidade e pouco comprometido em desenvolver interpretações que considerem variáveis culturais, o nacionalismo limita em grande parte o poder explicativo da teoria para outros contextos culturais. A segunda versão do particularismo, para o autor, relaciona-se com o entendimento do conceito de "público". A forma como a teoria lida com a dimensão pública acaba por dificultar o entendimento de que tanto o setor público quanto privado são socialmente constituídos. Além disso, desconsidera que as relações entre as duas esferas (pública e privada) são muito mais próximas do que se supõe e que as experiências em um setor podem ser úteis para o outro. Por fim, a terceira versão do particularismo se manifesta na preocupação excessiva com questões como eficiência, liderança, gestão e organização, desconsiderando a investigação de outros temas relevantes para a área.

O segundo limite das teorias modernas de administração pública consiste no cientificismo ou positivismo, expresso na contínua busca da formalização do estudo da administração pública como ciência. O cientificismo baseia-se na perspectiva de que os métodos das ciências naturais são aplicáveis a todos os campos de investigação, inclusive às Ciências Humanas: por meio dos rigorosos procedimentos científicos, um estudo seria capaz de aproximar o observador da verdade. Para os pensadores ligados às ideias pós-modernas, não existe uma verdade a ser encontrada, descrita e controlada. A realidade não existe em algum lugar a ser descoberto, ela é construída por meio das nossas interpretações sobre aquilo que nos cerca. A realidade social e as nossas explicações sobre ela são indissociáveis, continuamente organizadas, reorganizadas, negociadas e abertas a diversas outras interpretações. Para Farmer, as dificuldades da aplicação dos métodos científicos 


\section{ANA CLÁUDIA NIEDHARDT CAPELLA}

positivistas à administração pública tem sido objeto de intenso debate ao longo do desenvolvimento do campo. A discussão acerca das relações entre fato e valor, tema recorrente ao longo do desenvolvimento das teorias de administração pública, exemplificam a inadequação do modelo positivista à área.

O limite da tecnologia é apontado pelo autor como o terceiro aspecto característico da linguagem moderna da administração pública. Da mesma forma como outras áreas de conhecimento buscam apontar respostas tecnológicas para questões sociais, econômicas e políticas, a Administração Pública também procura oferecer respostas para os problemas de organização e gerenciamento. $\mathrm{O}$ processo de racionalização típico da modernidade levou o estudo da administração pública do estágio técnico - conhecimento pré-científico - a uma ciência baseada na tecnologia, ou seja, no conhecimento científico. Dessa forma, a área enfrenta os limites do cientificismo apontados anteriormente. Por outro lado, o autor mostra que a tecnologia predominante na administração pública é caracterizada pelo low-tech, ou seja, composta por conjuntos de práticas técnicas e procedimentos socialmente constituídos. As tecnologias de orçamento, organização, recursos humanos são, nessa perspectiva, um conjunto de práticas técnicas, voltadas para o desenvolvimento e aperfeiçoamento do instrumento tecnológico. Essas tecnologias, para o autor, tendem a ser permeadas pelo modismo, além de conterem aspectos potencialmente desumanizadores. O limite da área enquanto tecnologia baseada na ciência reside no paradoxo entre a administração pública como um sistema tecnológico e como elemento mobilizado por valores éticos.

A adoção do modelo de empresa como referência para a burocracia governamental consiste na quarta expressão da modernidade nas teorias de administração pública. Apesar da discussão sobre as diferenças entre organizações públicas e priva- das remontar aos primórdios do campo, a crítica particular de Farmer sobre a aplicação de princípios do modelo empresarial na administração pública se refere fundamentalmente aos aspectos de motivação envolvendo os servidores públicos, especialmente a ideia de que o funcionário público pode ser compreendido como um ator racional, movido pelo autointeresse. Direcionando suas críticas mais especificamente ao modelo da escolha pública (public choice), Farmer destaca que, embora as ideias de autores vinculados à abordagem tenham contribuído para gerar conhecimentos importantes para a área (estudos sobre o gasto público, por exemplo), as limitações da teoria econômica moderna se projetam sobre o entendimento da administração pública, sobretudo pelas profundas diferenças entre o setor público e os sistemas de mercado.

Finalmente, o quinto e último limite apontado pelo autor refere-se à hermenêutica modernista. A linguagem das teorias de administração pública é marcada pela contínua transformação de sentidos e significados. A área se desenvolve, segundo o autor, com base em contínuas reinterpretações de conceitos básicos, seja esta ação conduzida de maneira consciente, por autores que realizam análises críticas ou interpretativas, ou por meio de pensadores situados além do próprio campo da Administração Pública e que acabam por influenciar a área. Os limites das interpretações modernas se revelam no momento em que, segundo o autor, a busca de sentido defronta-se com o enfraquecimento da razão e da racionalidade (descentramento do sujeito), ou seja, quando a razão deixa de ser considerada como base do progresso humano. Nesse momento, a linguagem moderna da administração pública enfrenta limites muito claros, sendo necessário outro tipo de explicações para a área.

No lugar dessas características, típicas da linguagem da administração pública na modernidade, Farmer (1995) propõe tratar a teoria em 
termos daquilo que descreve como aspectos centrais da pós-modernidade: imaginização, desconstrução, desterritorialização e alteridade. Se na modernidade a racionalização se ampliou para diversos aspectos da sociedade, unindo ciência, tecnologia e interpretações sob o domínio da racionalidade, a imaginização assumiria papel central na sociedade pós-moderna. A imaginização consiste no processo de destacar o significado da imagem (a alegoria, a metáfora, o desenho, por exemplo) sem uma referência precisa, envolvendo processos ativos de criatividade. A imaginização envolve o pensar em sentido amplo, aberto às diversas possibilidades, rompendo com o pensamento racional, limitado ao factível. O autor desenvolve esse aspecto em outra obra, mostrando que a forma pós-moderna de pensar avança para além do usual, considerando aspectos que as formas tradicionais de pensamento tendem a reprimir e considerar sem importância:

Imagine that administration is not like a machine. The idea of the machinery of government is so culturally ingrained that it's hard to imagine this. [...] Imagine that administration is not top-down or hierarchical, relying on direction, coordination, and control from above. Let's call what is imagined open administration. [...]. Imagine that administration is not dominated so thoroughly by the symbolic system of the economy. Imagine that administration harbors no ethic of mere efficiency. Or imagine the opposite; imagine that administration embraces instrumental rationality even more fully. Imagine that administration is not infused by the professional model. Imagine (again) that administration is not typically reified, treated as if it were a natural kind. Imagine that administration is not group administration. [...] Imagine all of these changes together, and more. Imagine that in this way we can transform the status quo; imagine that we can kill the king! Then, imagine - play with ideas about - what possible worlds this imagining opens. Governance is worth contemplating, playfully. (FARMER, 2005, p. 3-6).

A desconstrução é uma forma de entendimento de um fenômeno que permite expor suas contrariedades e múltiplas interpretações. Embora não se constitua propriamente em um método, análise ou crítica, a desconstrução explora o caráter contraditório da linguagem, derivado dos múltiplos contextos - histórico, político, cultural, institucional - nos quais a linguagem produz as narrativas geralmente aceitas como "verdadeiras"4. $\mathrm{O}$ objetivo da desconstrução não consiste em oferecer uma interpretação alternativa ou mais "correta" e sim explicitar as pressuposições, contradições, exclusões presentes na narrativa. Farmer (1995) destaca duas narrativas que exemplificam como a teoria e a prática da administração pública moderna se sustenta. A primeira narrativa, típica da modernidade ${ }^{5}$, é a que aponta a objetividade como finalidade das teorias da administração pública, relacionando diretamente a qualidade de uma teoria a sua objetividade. Tomando como exemplo o texto clássico de Herbert Simon - "O comportamento administrativo" -, Farmer mostra que forças além do controle do autor (interesses da editora, características do mercado de livros em administração pública e do ambiente acadêmico, o contexto das outras obras que auxiliaram Simon na construção de sua análise, as interpretações particulares do autor sobre essas obras, entre outros fatores) exercem influência sobre o conteúdo do texto e que a objetividade, portanto, não subsiste à desconstrução. A segunda narrativa presente na administração pública moderna e diretamente relacionada à dimensão prática é aquela que elege a eficiência como objetivo da ação administrativa. O autor enfatiza que a eficiência não é um fato objetivo, mas uma construção social, ou seja, um conceito definido e redefinido cultural, política e historicamente. "Efficiency is a social construction, ambiguous in that it displays varieties of meanings" (Farmer, 1995, p. 199). No contexto da linguagem moderna da administração pública, a eficiência não apenas é representada como sendo o objetivo último da ação 


\section{ANA CLÁUDIA NIEDHARDT CAPELLA}

administrativa, mas também representada continuamente de forma favorável: eficiência designa algo positivo, enquanto ineficiência relaciona-se a algo negativo. A eficiência assume, assim, a dimensão de um conceito moral. Tal característica também é desconstruída pelo autor, que aponta exemplos históricos em que a eficiência não é necessariamente algo desejável (como no caso dos campos de concentração durante a Segunda Guerra Mundial). Desconstruindo a narrativa da eficiência e, com ela, as aplicações práticas do conceito, como a análise da relação de custo-benefício e as avaliações de desempenho, o autor mostra que tal desconstrução permite uma melhor apreciação dos textos nas condições particulares da pós-modernidade:

\footnotetext{
This postmodern situation is where the real and appearance have imploded, where bureaucracy is part of the swirl of images and appearances, where the world of production has been replaced by the world of seduction, and where public policy is subjected to politics run like show business. Seduction, images, and signs without referents constitute the postmodern administrative world. (FARMER, 1995, p. 208-209).
}

A desterritorialização - negação das formas modernas de entendimento das representações - é a penúltima característica da pós-modernidade analisada pelo autor. Todo conhecimento, na pós-modernidade, é desterritorializado em termos de suas características e organização. Na administração pública, isso significa, para Farmer, libertar a forma de pensar das estruturas organizacionais, força que codifica (territorializa) as características desse pensar. A desterritorialização ainda exerce impacto sobre a administração pública ao eliminar os limites disciplinares e as especialidades da área.

Por fim, a alteridade envolve a dimensão moral. No limite, as implicações da pós-modernidade para a administração pública levariam a atitudes éticas que o autor denomina "antiadministração".
A natureza da "antiadministração" é explicada pelo autor em termos de quatro atitudes pós-modernas com relação à alteridade: abertura para o "outro", para a diversidade, oposição às grandes narrativas e à ordem estabelecida.

\section{MILLER E FOX: A PRÁTICA DA ADMINISTRAÇÃO PÚBLICA E A CONSTRUÇÃ̃O DA REALIDADE}

De forma diferente de Farmer (1995), que conduz uma análise ampla sobre as características e os limites das teorias de administração pública modernas e analisa as contribuições do pensamento pós-moderno para a área, o estudo de Miller e Fox (2007) concentra-se na crítica ao modelo sistêmico de democracia, utilizando, para tanto, os argumentos pós-modernos. Os autores estruturam sua análise com base na desconstrução do chamado "loop model of democracy" de forma a evidenciar seus limites, discutir as alternativas a esse modelo - neoliberalismo, constitucionalismo, comunitarismo - e oferecer uma interpretação alternativa que pode ser chamada de pós-moderna, focalizando suas implicações sobre a administração pública.

O modelo de democracia criticado pelos autores consiste em um entendimento sistêmico sobre o processo decisório democrático que se inicia com a manifestação da vontade popular (entendida como a somatória das preferências individuais dos eleitores) no processo eleitoral, a formulação das políticas conduzidas pelos políticos eleitos, a implementação dessas políticas pela burocracia, e a avaliação expressa na reeleição ou na escolha de outros candidatos ou partidos. Os problemas desse modelo, tanto do ponto de vista empírico quanto teórico, já amplamente discutidos na literatura da ciência política, são analisados pelos autores principalmente em termos dos efeitos sobre a representação. Para os autores, a concepção mo- 
derna da representação envolve a chamada "metafísica da presença": ideia típica da modernidade que considera a existência imutável, neutra e real de uma "vontade popular", ideia marcada, sobretudo, pelo positivismo. Para os autores, os eleitores não necessariamente sabem o que querem/ desejam e não há vontade popular independente dos meios de comunicação, que influenciam em grande medida a agenda da opinião pública. Além disso, os candidatos, no sistema político atual, não competem com base em um conjunto de propostas cuidadosamente elaboradas sobre as políticas públicas a serem implementadas: no sistema eleitoral contemporâneo, as imagens são mais importantes do que o conteúdo. Por outro lado, os eleitores não votam, necessariamente, de acordo com as propostas apresentadas, de forma racional. Uma vez eleitos, os políticos são influenciados pelos grupos de interesse, comunidades de políticas e outros atores, podendo distanciar-se dos objetivos declarados nas plataformas eleitorais. A vigilância dos eleitores sobre o comportamento dos eleitos é insuficiente: as pessoas geralmente não se recordam em quem votaram, não acompanham as políticas propostas. Mesmo insatisfeitos, os eleitores continuarão votando e eventualmente reelegendo os políticos, independentemente da avaliação que fazem de seu desempenho.

Outra limitação desse modelo de democracia, além da própria questão da representação, reside na separação entre política e administração que permeia sua lógica de funcionamento. A dimensão política, representada pelas urnas, e a administração, manifesta na hierarquia e na cadeia de comando, permitiriam que os políticos eleitos exercessem controle sobre os servidores para que estes cumprissem a "vontade popular" de forma neutra. Tal modelo, para os autores, constitui uma narrativa típica da modernidade e sustenta a "administração pública ortodoxa": "Orthodoxy [...] was that enduring prescription of neutral public administration ascribed in the literature to Wilson (separation of politics and administration), Taylor (scientific management), and Weber (hierarquical control)" (MILLER e FOX, 2007, p. 3). O problema, para os autores, é que, apesar da intensa discussão, conduzida principalmente na literatura americana sobre as limitações da dicotomia entre política e administração, a administração pública permanece presa a esse modelo: nas teorias produzidas no campo, nos currículos das escolas, nas práticas reformistas.

A perspectiva ortodoxa é criticada pelos autores principalmente por meio da ideia de "hiper-realidade": uma forma de caracterizar a relação entre imagem e realidade ${ }^{6}$. A hiper-realidade designa uma situação na qual não é possível afirmar claramente a distinção entre o que é real e o que é simulação. A imagem, que um dia teria sido um mecanismo de representação da realidade (tal como um mapa a representar uma localidade), passa a mascarar a realidade, depois mascarar a ausência de uma realidade, até assumir seu próprio lugar, ou seja, a imagem converte-se em simulacro da realidade. Dessa forma, simulacros como programas de televisão não consistem em representações de uma determinada realidade, mas produzem as realidades que as pessoas experimentam ao assistir a eles. No limite, isso significa que a realidade deixa de ser uma possibilidade: os símbolos tomam o lugar daquilo que representam, tornando-se, eles próprios, a "realidade". Dessa forma, os significados são cada vez menos estáveis: palavras, imagens e signos são desconectados de seus referenciais (fenômeno designado epifenomenalismo) e passam a constituir seus próprios sentidos (tendência chamada autorreferenciação).

Para Miller e Fox (2007), o fluxo cada vez mais rápido da velocidade de transmissão, circulação e apreensão da informação (comunicação simbólica) alterou profundamente a natureza da comunicação no mundo contemporâneo. Os di- 


\section{ANA CLÁUDIA NIEDHARDT CAPELLA}

versos grupos e culturas são conectados por uma realidade transitória, instável e sujeita a rápidas mudanças. Não existe, para os autores, realidade que não seja midiatizada, e esse processo tem provocado profundas transformações no campo da Política e da Administração Pública.

Do ponto de vista político, uma das consequências da hiper-realidade reside na alienação de signos e palavras do discurso democrático. As palavras perdem a capacidade de produzir significados: tornam-se autorreferenciadas e constituem-se em epifenômenos, ou seja, são em grande parte efêmeras e adquirem sentido apenas num contexto limitado e para os indivíduos que integram esse contexto, não sendo válidas para todas as culturas. Assim, a dimensão ampla da cultura (a sociedade como um todo) se fragmenta, e em seu lugar são desenvolvidas comunidades do discurso, tendência denominada "neotribalismo". Essas características tornam ideias como "vontade popular" e "discurso político" crescentemente problemáticas. Esvaziado da possibilidade de um sentido amplo, o simbólico assume o protagonismo, o simulacro assume o lugar da imagem, e o espetáculo da mídia toma o lugar do debate público e da deliberação democrática. É importante observar que a mediação da política pelo simbólico não é propriamente algo recente. A diferença é assim explicitada pelos autores:

\footnotetext{
Modernity, however reified the explanatory systems used to justify it, had more stable metanarratives. And these were at least vulnerable to evidence of internal contradiction. There were truth functions available for use by opponents as well as proponents of the status quo.

(MILLER e FOX, 2007, p. 71).
}

Da mesma forma, do ponto de vista da administração, a dimensão simbólica tem ocupado lugar cada vez mais central: "In public administration practice, it is now more important to show you did your job that to actually do your job. The signifier has taken over the signified. This irony is the consequence of various attempts to measure performance, results and outcomes" (Miller e Fox, 2007, p. 12)7. Para os autores, termos como "desempenho orçamentário", "gestão orientada para resultados", "avaliação de desempenho" fazem parte do vocabulário contemporâneo da administração pública. Essas categorias são apresentadas como sendo "reais", objetivas e verificáveis do ponto de vista empírico. No entanto, a "realidade" é algo extremamente difícil de medir ou representar.

\begin{abstract}
In public administration, the drive for empirical evidence mostly generates pressure for a good show amidst the atmospherics of accountability. Performance symbols such as "crime rate reduction," or "test score improvement," or "membership increase" do not need reality as backup. The symbols are their own referents, the outcome of play of the game. In this way, managerialism betrays reality, vacating it of substance and inserting pleasant-sounding progress in its place. Image is the essence, the new reality. (MILLER e FOX, 2007, p. 15).
\end{abstract}

A lógica da gestão orientada para resultados implica o desenvolvimento de indicadores que auxiliam na focalização dos resultados esperados com base nos recursos alocados. Implica, igualmente, o estabelecimento de objetivos, para que o progresso seja acompanhado. O problema, para os autores, é que avaliar uma atividade governamental é uma ação sempre problemática, pois as medições de desempenho frequentemente falham do ponto de vista técnico e, além disso, são passíveis de falsificação. Os resultados não necessariamente refletem uma realidade, por vezes são utilizados como estratagemas por gerentes que apresentam as atividades sob sua responsabilidade como eficientes e efetivas:

Reports that show magnificent results may appear impressive, but such reports corrupt the denotative meaning of the term results. In the process of outcomes measurement, all the meaningful symbols 
- performance, results, and outcomes - are debased.

The ambiguity about government performance that was supposed to become transparent and unmistakable has spread; now the words themselves - performance, results, and outcome - have become ambiguous.

(MILLER e FOX, 2007, p. 13-14).

A análise dos autores ainda destaca a importância da perspectiva construtivista para a administração pública, alternativa que permitiria um melhor entendimento da dinâmica organizacional e das práticas de gestão. Utilizando teorias construtivistas, os autores "desconstroem" a ideia de burocracia, mostrando que o termo não capta a totalidade das ações no setor público, servindo, em vez disso, como símbolo que agrega eventos diversos e frequentemente contraditórios sob um mesmo signo. Para entender o debate contemporâneo sobre a desburocratização, por exemplo, seria preciso compreender a burocracia em seus diferentes sentidos.

A solução apresentada pelos autores para a teoria democrática, dada a limitação do modelo sistêmico no contexto da pós-modernidade, é a criação e manutenção de um "discurso autêntico": o debate aberto, inspirado no pensamento habermasiano ${ }^{8}$. A administração pública, para os autores, teria um papel fundamental no aprofundamento da democracia deliberativa ao estabelecer mecanismos de comunicação autênticos, baseados em redes e outras formações desterritorializadas. Tal arena de debate público só seria possível mediante algumas "garantias para o discurso":

One has to involve oneself with sincerity (creating trust), and intentionally in the situation (creating orientation towards solving a problem at hand). Furthermore, one must be attentive (creating engagement, but also the ability to listen), and give a substantive contribution (creating a sense that the process is going forward) Fox e Miller (BOGASON, 2007, p. 243).
Assim, os autores destacam a importância da administração pública como arena para a comunicação, como antídoto para o totalitarismo e outras formas de uso de poder direcionadas para silenciar ou eliminar participantes do debate público.

\section{CONTRIBUIÇÕES E DESAFIOS DA PERSPECTIVA PÓS-MODERNA PARA AS TEORIAS DA ADMINISTRAÇÃO PÚBLICA}

Uma das maiores contribuições que a perspectiva pós-moderna pode oferecer à administração pública consiste nos aspectos metodológicos, fundamentalmente na abordagem da investigação naturalista (naturalistic inquiry) ou construtivista. Tal método oferece uma abordagem "pós-positivista" que tem se revelado bastante promissora em pesquisas recentes em outras áreas de conhecimento (como no campo de Políticas Públicas, por exemplo). Farmer (1995) aponta o trabalho de Lincoln e Guba (1985) como sendo capaz de captar os elementos centrais ao pensamento pós-moderno e orientar o desenvolvimento de pesquisas empíricas. A investigação naturalista proposta pelos autores baseia-se em cinco axiomas (crenças básicas), como explica Farmer. Em primeiro lugar, predomina a visão de que as realidades são múltiplas, construídas e holísticas, em contraposição à ideia positivista de que a realidade é única, tangível e fragmentável. O segundo elemento orientador do modelo reside na percepção da investigação como sendo indissociável dos valores e ideologias, perspectiva oposta ao positivismo. A perspectiva de que o sujeito e o objeto são inseparáveis consiste no terceiro axioma, em franca oposição à visão positivista na qual pesquisador e conhecimento são independentes. As restrições quanto às possibilidades de generalização figuram 


\section{ANA CLÁUDIA NIEDHARDT CAPELLA}

em outra premissa do modelo naturalista, que considera hipóteses de trabalho válidas apenas para um determinado contexto, contrariamente à intenção positivista de oferecer explicações generalizantes, descoladas do contexto e do tempo. A impossibilidade de distinção entre causa e efeito é o último axioma da investigação naturalista. $\mathrm{O}$ pressuposto é que as entidades existam em relação de mútua influência, ao contrário da perspectiva positivista em que as causas, entendidas como reais, podem ser claramente relacionadas aos efeitos. Essas ideias básicas sobre a realidade e o conhecimento organizam as características operacionais da proposta naturalista. Frederickson e Smith (2003, p. 157) apresentam algumas aplicações da abordagem naturalista realizadas em diferentes pesquisas no campo da administração pública, mencionando estudos dedicados a temas diferentes e que incorporam as ideias pós-positivistas.

Outra contribuição da abordagem pós-moderna para a área de administração pública é a ênfase na análise das narrativas, decorrente importância atribuída à linguagem. Farmer (1995) mostra como desconstruir a ideia de eficiência burocrática, Fox e Miller (2007) buscam desconstruir o próprio conceito de burocracia. A análise pós-moderna questiona a manutenção de "verdades", destacando que as categorias que se apresentam como fatos objetivos (burocracia, por exemplo) baseiam-se em pressuposições, geralmente assentadas sobre oposições e metáforas, engendradas pelo usuário da linguagem, constituindo-se, sobretudo, numa relação de poder. Assim, a análise pós-moderna poderia ser vista como um esforço no sentido de negar o poder constituído e expresso por meio das "verdades", abrindo espaço para a manifestação das vozes marginalizadas. O "discurso autêntico" de Fox e Miller (2007) representa a construção de um espaço institucionalizado para a comunicação aberta em que diferentes comunidades discursivas poderiam se manifestar.
Do ponto de vista metodológico, considerar a importância da linguagem alinha-se com a perspectiva pós-positivista, na qual as práticas argumentativas são entendidas como elementos ativos de construção da realidade, e não da "descrição" desta. Estudar criticamente a produção discursiva, em vez de tomá-la como "verdade", é o ponto de partida das desconstruções realizadas pelos pós-modernos. Se a linguagem é a ferramenta por meio da qual a realidade é construída, a prática discursiva (a forma como os indivíduos ou grupos produzem as realidades sociais) constitui-se numa importante fonte para a análise empírica. A compreensão das interpretações dos burocratas sobre as ações que realizam, por exemplo, pode ser conduzida por meio da análise de histórias e narrativas elaboradas por esses atores, nas quais são produzidos e reproduzidos os sentidos sobre o universo burocrático. Além disso, a investigação da linguagem em organizações públicas contribui para o entendimento não apenas do que é declarado, mas daquilo que não é dito e é sistematicamente ignorado. Assim, a perspectiva metodológica das abordagens pós-modernas pode contribuir para uma importante reflexão dos administradores públicos sobre suas visões do mundo burocrático e da prática administrativa, bem como chamar a atenção para as consequências políticas de suas opções na adoção e disseminação de "verdades" específicas. Esse aspecto é importante não apenas para a reflexão sobre a prática da administração pública, mas também para o próprio desenvolvimento teórico na área.

As far as studying government is concerned, this
approach [postmodernism] is perhaps most fruitful in
an educational environment with advanced graduated
students or mid-career professionals, because it
requires a solid knowledge basis in the study of public
administration. (RAADSCHELDERS, 2008, p. 943).

A perspectivas analíticas propostas pelo pensa- 
mento pós-moderno, como a desterritorialização, também oferecem alternativas para o questionamento de padrões fixos de pensamento gerados por categorias tomadas como "verdades". Todas as organizações constituem-se de territórios, como as unidades organizacionais fragmentadas ao longo da estrutura, os processos de trabalho que se desenvolvem nesses espaços, as distintas categorias de profissionais que empregam seus saberes específicos no exercício das funções segmentadas nesses espaços e outras manifestações da divisão do trabalho. De maneira semelhante, a alteridade, outro elemento presente nas abordagens pós-modernas, permite evidenciar as consequências das ações administrativas. A consciência do "outro moral" estimula a crítica da abordagem tecnocrática e, no limite, converte-se na ideia de Farmer (1995) sobre a "antiadministração".

Apesar de promissora, a perspectiva pós-moderna não está livre de críticas. Uma observação bastante pertinente, com relação às contribuições para o campo de administração pública, questiona o caráter de novidade que as ideias presentes na perspectiva pós-moderna realmente representam. Diversas limitações presentes nas teorias modernas de administração pública, apontadas por Farmer (1995), Miller e Fox (2007) e outros, são recorrentes na área, tendo sido desatacadas por diferentes autores em diversos períodos. A crítica ao modelo burocrático e a análise de suas disfunções têm sido um tema constante em estudos que adotam os mais diferentes referencias teóricos ao longo da história da Administração Pública como área de conhecimento. Da mesma forma, questionam-se as contribuições efetivas do pensamento pós-moderno para a área, uma vez que muitos dos caminhos apontados por autores declaradamente filiados a essa abordagem são também trilhados por outros pensadores. A dimensão central da linguagem e da cultura, o poder da retórica, a recorrência das ideias nas teorias administração pública são aspectos já in- vestigados por autores sem vinculação declarada a uma abordagem pós-moderna9 ${ }^{9}$. De forma semelhante, o ideal de participação e inclusão presente, por exemplo, no "discurso autêntico" de Miller e Fox não é propriamente uma novidade, tendo sido tema presente nas críticas da "nova administração pública" (movimento desenvolvido nos Estados Unidos na década de 1960) à "administração pública clássica", como mostra Denhardt (2004). Os limites da separação entre política e administração, a relação entre fatos e valores, a discussão sobre eficiência versus equidade, hierarquia versus participação, são temas recorrentes e que acompanham o desenvolvimento teórico do campo, independentemente do enfoque da pós-modernidade.

Outro aspecto a ser considerado na obra dos autores pós-modernos é a dificuldade em se afastarem do próprio paradigma da modernidade que criticam. Ao mesmo tempo que Farmer desconstrói as metanarrativas da modernidade, oferece uma alternativa idêntica: a metanarrativa da pós-modernidade. Assim, alguns autores criticam a maneira como Farmer se apropria do pensamento pós-moderno ao mostrar que ele reinventa as teorias modernas e não as transforma, tendo grandes dificuldades para se afastar da forma moderna de pensar:

Farmer frames his discussion of modernism and postmodernism in distinctively modernist language. Talk of limits, or dead-ends, or blind spots, is modernist talk. [...)] To say a way of talking - in the big sense of a conceptual scheme - is limited is to say we can compare conceptual schemes and determine which one is more suited to the job we have in mind. Such comparison [...] is a modernist move (TENNERT e WEAVER, 2000, p. 333).

Um olhar mais atento revela que o autor não pretende adotar uma postura de rompimento com o paradigma da modernidade, uma vez que afirma não se tratar de rejeitar a modernidade, 


\section{ANA CLÁUDIA NIEDHARDT CAPELLA}

mas sim de compreendê-la. Segundo o autor, "In a period of multiple discourse, it was discussed how no text is privileged. Neither modernity's nor postmodernity texts need to be denied; on the contrary, their contributions should be appropriately understood" (FARMER, 1995, p. 248). Essa observação é importante para pensarmos os desafios e possibilidades da incorporação das ideias da pós-modernidade no ensino de administração pública. Como conciliar, por exemplo, a análise da eficiência burocrática como construção social e, ao mesmo tempo, como parte integrante da cultura burocrática prevalecente nas organizações públicas? A burocracia pode ser entendida como um epifenômeno na abordagem pós-modernista, mas o cotidiano das organizações públicas é composto por estruturas, processos organizacionais e pessoas, dentro das limitações modernas assinaladas por Farmer. Talvez a mensagem mais importante de Miller e Fox seja a de que o mundo da prática, nas burocracias públicas, é muito mais caótico, mediado por símbolos, imagens e elementos da cultura popular. A abordagem pós-moderna é útil para mostrar que a administração pública é mais dinâmica e menos ordenada do que supomos, e que a linguagem é um instrumento essencial de poder.

\section{CONSIDERAÇÕES FINAIS}

O presente estudo buscou apresentar e discutir a utilização das "lentes" pós-modernas no estudo da administração pública. A aproximação entre os referenciais presentes no pensamento pós-moderno e as teorias de administração pública tem sido intensificada a partir dos anos 1990, principalmente por meio da reflexão de autores americanos. Essa relação é marcada pela crítica aos limites da modernidade, sobretudo a dois aspectos específicos: a burocracia como modelo or- ganizacional e o ideal de racionalidade. Outra crítica incorporada pelos teóricos da administração pública pós-moderna é o que Farmer denomina cientificismo: a crença no progresso baseado na ciência, identificada, pelos pós-modernos, com o positivismo. Assim, as abordagens pós-modernas da administração pública procuram desconstruir as grandes narrativas ou linguagens formais sobre as quais a área se constituiu, destacando elementos como a interpretação, a subjetividade, além da ausência de ideal de integração. Como contribuições ao campo, podemos assinalar a abordagem construtivista (pós-positivista) e a ênfase na linguagem, aspectos que podem fornecer alternativas metodológicas para a investigação em administração pública, ampliando o foco da área de organizações e processos administrativos para a linguagem, poder e cultura.

Talvez seja importante para os estudos em Administração Pública compreender como outros campos do conhecimento incorporaram as ideias relacionadas à pós-modernidade. O modelo racionalista e o positivista, objeto de crítica das teorias pós-modernas de administração pública, têm sido fortemente criticados, por exemplo, no campo de políticas públicas. A importância da linguagem e do processo argumentativo na análise de políticas públicas tem sido destacada por diversos autores (MAJONE, 1989; FISCHER e FORESTER, 1993; STONE, 2002) na chamada "abordagem das ideias" ou perspectiva "pós-positivista". A busca de referenciais que se distanciem do modelo racionalista e do positivismo pode ser um ponto de convergência para os estudos desenvolvidos em ambas as áreas.

\section{NOTAS}

\footnotetext{
1 Para uma análise aprofundada sobre a pós-modernidade, consultar: Harvey, David. Condição pós-moderna. São Paulo: Loyola, 1992; Giddens, Anthony. As consequências da modernidade.
} 
São Paulo: Unesp, 1991; Lyotard, Jean-François. A condição pósmoderna. 8. ed. Rio de Janeiro: José Olympio, 2004. Bauman, Zygmunt. A Modernidade Líquida. Rio de Janeiro: Jorge Zahar, 2001.

2 O. C. McSwite é o pseudônimo empregado pelos professores Orion White e Cynthia McSwain em artigos elaborados conjuntamente.

${ }^{3}$ A ideia de jogos de linguagem foi originalmente desenvolvida pelo filósofo alemão Ludwig Wittgenstein em Investigações filosóficas. São Paulo: Nova Cultural (Col. Os Pensadores), 2000.

${ }^{4}$ O filósofo francês Jacques Derrida desenvolve a ideia de desconstrução na obra Gramatologia. São Paulo: Perspectiva, 1973.

${ }^{5}$ Para uma discussão sobre as "grandes narrativas" da modernidade, como elementos de justificação do projeto racionalista, consultar Lyotard, Jean-François. A condição pós-moderna. 8. ed. Rio de Janeiro: José Olympio, 2004,

6 Sobre o conceito de hiper-realidade, consultar: Baudrillard, Jean. Simulacros e simulação. Lisboa, Antropos, 1991.

${ }^{7}$ Grifo do original.

${ }^{8}$ Sobre a teoria do discurso em Habermas, consultar: Habermas, J. Between Facts and Norms: Contributions to a Discourse Theory of Law and Democracy. Cambridge: MIT Press, 1996.

${ }^{9}$ Um exemplo é o estudo conduzido por Christopher Hood, The Art of State: Culture Rhetoric and Public Management. Oxford, Oxford University Press, 1998.

\section{REFERÊNCIAS}

BOGASON, Peter. Postmodernism and American public administration. Administration \& Society, v. 33, n. 2, p. 165-193, 2001.

Postmodern Public Administration. In: FRELIE, E.

et. al. The Oxford Handbook of Public Management. Oxford, Oxford University Press, 2007.

DENHARDT, Robert B. Theories of Public Organization. Belmont, CA: Thomson/Wadsworth, 2004.

FARMER, David J. The Language of Public Administration. Alabama, University of Alabama Press, 1995.

To Kill The King: Post-Traditional Governance and Bureaucracy. New York, M. E. Sharpe, 2005.

FISCHER, Frank; FORESTER, John (Eds.). The Argumentative Turn in Policy Analysis and Planning. Durham, Duke University Press, 1993.

FOX, Charles J.; MILLER, Hugh T. Postmodern Public Administration: Towards Discourse. London, Sage, 1995.
FREDERICKSON, H. G.; SMITH, Kevin. The Public Administration Theory Primer. Oxford, Westview Press, 2003.

HARMON, Michael M. Action Theory for Public Administration. New York, Longman, 1981.

JUN, Jong S. The Social Construction of Public Administration: Interpretative and Critical Perspectives. New York, State University of New York Press, 2006.

LINCOLN, Yvonna S.; GUBA, Egon G. Naturalistic Inquiry. London, Sage, 1985.

LYNN JR., Laurence E. Public Management as Art, Science, and Profession. Chatham, Chatham House Publishers, 1996.

MAJONE, Giandomenico. Evidence, Argument \& Persuasion in the Policy Process. New Haven/London, Yale University Press, 1989.

MCSWITE, O. C. Legitimacy in Public Administration: A Discourse Analysis. Thousand Oaks, CA: Sage, 1997.

MILlER, Hugh T.; FOX, Charles J. Postmodern Public Administration. Armonk, NY: M. E. Sharpe, 2007.

RAADSCHELDERS, Jos C. N. Understanding government: four intellectual traditions in the study of public administration. Public Administration, v. 86, n. 4, p. 925-949, 2008.

SOUZA, Celina. Pesquisa em Administração Pública no Brasil: uma agenda para o debate. Revista de Administração Pública, v. 32, n. 4, jul-ago, p. 43-61, 1998.

SPICER, Michael W. Public Administration and the State. Tuscaloosa, University of Alabama Press, 2001.

STIVERS, Camilla. Gender Images in Public Administration: Legitimacy and the Administrative State. Thousand Oaks, CA: Sage, 2002.

STONE, Deborah. Policy Paradox: The Art of Political Decision Making. New York, Norton \& Company, 2002.

TENNERT, John; WEAVER, William G. Postmodern public administration: a sheep in wolf's clothing? Southeastern Political Review, v. 28, n. 2, p. 319-349, 2000.

WHITE, Jay D. Taking Language Seriously: the Narrative Foundations of Public Administration Research. Washington, DC, Georgetown University Press, 1999. 